\title{
Population screening for BRCA1/BRCA2 mutations: lessons from qualitative analysis of the screening experience
}

\author{
Sari Lieberman, MSc ${ }^{1,2}$, Amnon Lahad, MD, MPH ${ }^{1,3}$, Ariela Tomer, MSc ${ }^{1,2}$, Carmit Cohen, MHA ${ }^{1,2}$, \\ Ephrat Levy-Lahad, MD ${ }^{1,2}$ and Aviad Raz, PhD ${ }^{4}$
}

\begin{abstract}
Purpose: Population screening for $B R C A 1 / B R C A 2$. mutations is being considered for Ashkenazi Jews (AJ) because $2.5 \%$ carry recurrent deleterious mutations and effective cancer prevention exists. This study aimed to provide a qualitative focus on perspectives of individuals, particularly carriers, who were tested through a screening trial. In this trial, the pretest process included only written information.
\end{abstract}

Methods: Interviews were performed with 26 carriers and 10 noncarriers who participated in a BRCA population screening trial for AJ.

Results: Attitudes toward screening were generally positive. The main motivator for testing was knowledge of $B R C A$ status to enable cancer risk reduction. Knowledge of carrier status, although challenging, was thus viewed as health-empowering. The screening paradigm was sensed as increasing awareness and as overcoming access, referral, and familial barriers. Streamlining the pretest process was positively perceived as offering gradual, stepwise knowledge commensurate with test results. Participants were concerned that health systems provide the necessary conceptual and infrastructural framework and that individual autonomy be maintained.

Conclusions: $B R C A$ screening in $\mathrm{AJ}$ is viewed favorably, even by carriers. Stepwise acquisition of knowledge based on test results was viewed as most relevant to the screening context. Screening program development should account for safeguarding autonomy and providing requisite post-test services.

Genet Med advance online publication 1 December 2016

Key Words: Ashkenazi Jewish; BRCA; population screening; psychosocial outcomes; qualitative analysis

\section{INTRODUCTION}

General screening of BRCA1 and BRCA2 mutations has been proposed for the Ashkenazi Jewish (AJ) population, in which $2.5 \%$ of individuals carry one of three deleterious founder mutations, ${ }^{1-4}$ and other BRCA1/BRCA2 mutations are rare. ${ }^{5,6} \mathrm{~A}$ population-based approach is also motivated by consistent observations that approximately $50 \%$ of carriers do not have a suggestive family history, ${ }^{3,7,8}$ despite high risks for breast and ovarian cancer. ${ }^{7}$ Carriers identified can utilize highly effective prevention measures that significantly decrease morbidity and mortality, especially risk-reducing salpingo-oophorectomy. ${ }^{9} B R C A$ screening in $\mathrm{AJ}$ thus fulfills World Health Organization screening criteria ${ }^{1,10,11}$ and has also been shown to be highly cost-effective. ${ }^{12}$

To examine the feasibility of $B R C A$ screening for $A J$, we performed a BRCA screening-implementation trial. ${ }^{13}$ Before testing, participants received written information without traditional genetic counseling and completed a family-history questionnaire. After testing, in-person genetic counseling was provided to all carriers as well as to all noncarriers who reported a significant family history. Noncarriers without a significant family history of breast/ovarian cancer received a letter summarizing results and routine surveillance recommendations.

In this trial, as in other population-based screening studies, quantitative analysis of psychosocial outcomes essentially reflected the experiences of noncarriers, who comprise the vast majority of participants. We identified 32 carriers among 1,771 trial participants (1.8\%); carrier rates in previous studies of AJ ranged from 1.1 to $2.4 \%{ }^{12,14}$ Exploring the perspectives of carriers identified through general screening thus requires indepth qualitative analysis, which has not yet been performed in this setting. A particular concern is the response to unexpected detection of carrier status in individuals with a nonsuggestive family history, who would not have been tested if not for a screening program. Our aim was to gain a deeper understanding of the experience and concerns of screened individuals, both carriers and noncarriers, in order to inform the design and delivery of future population screening.

\section{Participants}

\section{MATERIALS AND METHODS}

This qualitative study was approved by the Shaare Zedek Medical Center institutional review board, and participants provided written informed consent. Participants were recruited among those in a trial of $B R C A 1 / B R C A 2$ population screening for AJ. Screening trial participants were either self-referred or recruiter-enrolled and were tested for common mutations (BRCA1-185delAG (c.68_69delAG), 5382insC (c.5266dupC), and BRCA2-6174delT (c.5946delT)). ${ }^{13}$ Interviews were offered to all carriers identified in the screening trial as well as to noncarriers from the same study.

${ }^{1}$ Faculty of Medicine, Hebrew University of Jerusalem, Jerusalem, Israel; ${ }^{2}$ Medical Genetics Institute, Shaare Zedek Medical Center, Jerusalem, Israel; ${ }^{3}$ Department of Family Medicine, Clalit Health Services, Jerusalem, Israel; ${ }^{4}$ Department of Sociology and Anthropology, Ben-Gurion University of the Negev, Beer Sheva, Israel. Correspondence: Ephrat Levy-Lahad (lahad@szmc.org.il) and Aviad Raz (aviadraz@bgu.ac.il) 
Inclusion criteria in the screening trial were $\mathrm{AJ}$ ancestry, age $\geq 25$ years, no cancer history, no previous $B R C A$ testing, and no previously known familial $B R C A$ mutation. Family history was classified as having no, low, moderate, or high likelihood of hereditary breast-ovarian cancer, as previously published. ${ }^{8,13}$

\section{Interviews}

Interviews were semistructured; the structured component included questions regarding interviewees' opinions about population screening, the streamlined screening process versus traditional in-person pretest counseling (which they did not experience), satisfaction with the screening process, and whether they would recommend screening to others (Supplementary Table S1 online). Interviews were conducted 12-18 months after test results, lasted approximately 1 hour, were audiotaped with participants' consent, and were transcribed verbatim. Transcripts were qualitatively analyzed using Atlas.ti for recurring themes within interviews and across groups of respondents. ${ }^{15,16} \mathrm{An}$ inductive, grounded theory approach was preferred for this study because this group has not been extensively studied and their numbers are currently small. See Supplementary Information online for details.

\section{RESULTS}

We interviewed $26 / 32$ (81\%) carriers identified through the screening trial. One had died, two were inaccessible, and three refused (no reason was provided). Sociodemographic characteristics were similar in interviewed vs. noninterviewed carriers (Table 1). Family history was moderately to highly suggestive of hereditary breast-ovarian cancer in 15/26 (58\%) (Table 1). To assess noncarriers' views, we initially contacted 13 noncarriers; 10 consented and 3 refused to be interviewed. The emanating themes and attitudes regarding population screening and a streamlined testing process were similar for noncarriers and carriers, except where noted, reaching interpretive saturation for these topics. Noncarrier interviewees were sociodemographically similar to carriers, except for being somewhat older (Table 1), reflecting the age difference between carriers and noncarriers in the entire study. ${ }^{13}$

Although respondents discussed a host of issues related to risk, identity, and autonomy, we focus here on themes specific to population screening and a streamlined testing process. Quotes are from women participants unless otherwise indicated.

\section{BRCA screening: general attitude and motivation}

The majority-21/26 carriers and 9/10 noncarriers-expressed unequivocally positive attitudes toward the genetic screening process. The remainder had both positive and negative reflections, as detailed below. The main motivator for BRCA testing was ascertainment of genetic status. This was perceived as the major benefit of testing, enabling accurate risk assessment and guiding subsequent medical actions. All post-childbearing carriers interviewed had undergone risk-reducing salpingooophorectomy. BRCA screening was seen as an opportunity for gaining personal knowledge, whether or not participants were previously concerned about breast cancer in general or their family history in particular.

\begin{abstract}
"Breast cancer has always been on my mind. ...I see people getting it...I want to know what my chances are...if there are ways to protect myself...I always want to know as much as I can." (31-year-old carrier, low-likelihood family history)
\end{abstract}

\section{Overcoming access, referral, and familial barriers}

Some themes were specific to participants who had previously considered or attempted $B R C A$ testing because of suggestive family history. These participants regarded the screening paradigm as a solution for bureaucratic hurdles:

"I call Hospital X and they say-call your HMO clinic. I call the HMO clinic, and they said-go to Hospital X..." (32-year-old carrier, high-likelihood family history, describing 2 years of unsuccessful efforts)

A 28-year-old carrier with a high-likelihood family history who was unable to obtain insurance coverage for a long time said "The whole testing issue was ultimately forgotten." Her sister-in-law urged her to be tested: "'They won't cover it', I told her, what can I do?'. She told me about this study...and this is how I...had the test."

Restrictive family history-based referral criteria precluded testing for some participants, even those concerned about their risk.

"My family physician....and my Ob/Gyn didn't refer me... When my mother had melanoma we asked the doctors if we need to do the genetic test. They said no, it's unrelated, it isn't familial." (38-old-year carrier, family history of nonspecific cancers)

Many respondents discussed the implications of requiring cooperation by affected relatives and recognized the advantage of circumventing this prerequisite.

"[They] told me that I am not the one to test. Because my mother is dead, this meant testing my grandfather...who is really not interested. So I just forgot about it." (28-year-old carrier whose mother had paternally inherited predisposition and died of breast cancer)

"My sister [diagnosed with breast cancer at age 33] is my opposite...she...doesn't want to know...I understood from the counselor [they should] ...first test my sister. I told my sister... and she isn't speaking to me ever since." (36-year-old carrier)

\section{Lack of awareness or support by medical personnel}

Lack of physician awareness or support was described as a barrier, discouraging testing in some cases-for example: "You are too young, it isn't relevant" or: "If [family history] is paternal, 
Table 1 Sociodemographic characteristics of interview participants (carriers and noncarriers) and nonparticipants (noninterviewed carriers)

\begin{tabular}{|c|c|c|c|c|c|c|}
\hline & & $\begin{array}{l}\text { Interviewed } \\
\text { carriers }\end{array}$ & $\begin{array}{c}\text { Noninterviewed } \\
\text { carriers }\end{array}$ & $\begin{array}{c}P \\
\text { value }^{\mathrm{a}}\end{array}$ & $\begin{array}{l}\text { Interviewed } \\
\text { noncarriers }\end{array}$ & $\begin{array}{c}P \\
\text { value }^{b}\end{array}$ \\
\hline Mean age (SD) & & $N(\%)$ & $N(\%)$ & & $N(\%)$ & \\
\hline Gender & Female & $21(81)$ & $5(83)$ & & $8(80)$ & \\
\hline Age & $<50$ years & $14(54)$ & $3(50)$ & NS & $3(30)$ & NS \\
\hline Enrollment method & Self-referral & $19(73)$ & $2(33)$ & & $7(70)$ & \\
\hline \multirow{2}{*}{$\begin{array}{l}\text { Family history: likelihood } \\
\text { of } \mathrm{HBOC}^{c}\end{array}$} & None-low & $11(42)$ & $2(33)$ & NS & $4(40)$ & NS \\
\hline & Moderate-high & $15(58)$ & $4(66)$ & & $6(60)$ & \\
\hline
\end{tabular}

HBOC, hereditary breast-ovarian cancer; NS, not significant.

a $P$ value (Fisher's exact test) for comparison of interviewed vs. noninterviewed carriers. ${ }^{b} P$ value (Fisher's exact test) for comparison of interviewed noncarriers versus interviewed carriers. 'Likelihood of $\mathrm{HBOC}$ was assessed using family-history questionnaires as previously described. 8,13

there is no need to test." A male carrier said his physician told him that $B R C A$ testing was "unnecessary" for men.

Some care providers were not supportive of risk-reduction measures in carriers, particularly those without a family history:

"The nurse who prepped me for my oophorectomy told me: 'This is what happens when you have unnecessary tests.....I asked a very good friend who is a [prominent] physician what would he do in my place, and he said decisively 'I wouldn't have unnecessary tests." (47-year-old carrier, no family history)

\section{Importance of public awareness}

"After Angelina Jolie, there was so much [discussion] about this....She did real good by essentially saying 'go get tested." (60-year-old carrier, low-likelihood family history)

Public awareness was viewed as important but currently insufficient. Lack of awareness is not surprising in participants whose family history does not meet current clinical testing criteria. However, seven carriers who were aware of having a suggestive family history said they had not known about $B R C A$ testing.

"I saw the study poster downstairs and decided to come. In a way this was a coincidence. However, the poster spoke to me, since I was already concerned....I have a lot of cancer cases in my family, but I didn't know about specific mutations. Not at all." (53-year-old carrier, moderate-likelihood family history)

The screening process was viewed as increasing both awareness and access:

"By chance I was available. ...That saved me...It was divine intervention; if I hadn't been tested it could have been found too late. ... They should go from woman to woman...so more women know and understand. Those who don't want to will not get tested. ...just like mammography is important, perhaps being diagnosed as a carrier is even more important." (66-year-old carrier, moderate-likelihood family history, enrolled at a mammography center)

\section{Coping with knowing}

Five of 26 carriers felt ambiguity regarding $B R C A$ testing. For four of these five, carrier status was unexpected because they had no significant family history:

"I think I should say [the genetic test] is a positive thing, there is no choice, I need to answer from my head. My heart...it doesn't want to know too much." (53-year-old carrier, low-likelihood family history)

"What I know may have helped me...but [consider a] woman who doesn't know yet. She can't be helped, but maybe she doesn't need this help and meanwhile she lives peacefully...no MRI or mammography every 6 months, no oophorectomy." (47-year-old carrier, no family history)

Information regarding cancer risks can cause anxiety and stress in carriers, regardless of the counseling format. We observed a wide variety of emotional responses in carriers. Some reflected awareness, but not anxiety:

"It didn't make me stressed or anxious. Look, I am now more aware of little things-I need someone by my side...it has some implications. Even for entering a relationship...straightaway I said I would like an agreement that this does not obligate [him] in any way. It got me thinking about things that I hadn't considered so much before." (60-year-old divorced carrier, no family history) 
Some carriers expressed general anxiety concerning themselves, relatives, and children; however, this was not perceived to have reduced their quality of life and they remained satisfied with having been tested. Two women carriers, both single, with no family history, expressed significant anxiety:

“...When my friend told me that I'm a time bomb, my life changed...Ever since, I started having stomach aches...I was in unbelievable stress." (54-year-old carrier, low-likelihood family history)

However, this was the only respondent who was unsure about whether she would still have chosen to undergo BRCA screening. The second respondent who expressed significant anxiety, nevertheless said that a year after being tested she realizes that the test was a good thing for her. Irrespective of their personal reactions, all respondents noted the need for post-testing psychological support.

\section{Health-system implications: routinization and preservation of autonomy}

Many participants suggested that routinization of genetic testing could overcome medical and social barriers:

"This test should be done by the family physician. When you come he opens your file and asks-were you tested for $B R C A$ ? It should be as simple as that. It seems basic." (32-year-old carrier, high-likelihood family history).

"If it becomes commonplace, it will be seen as simpler, nothing exceptional-you can treat and prevent." (60-yearold carrier, no family history)

However, routinization was also recognized to have consequences for both the health system and individuals. Respondents commented that health systems would need to accommodate a much larger number of carriers and to address gaps in care. For example, a few carriers mentioned that even in multidisciplinary carrier clinics, psychological support was insufficient. Another concern was preservation of autonomy and personal choice despite possible routinization.

"It's a very personal decision. You may offer the test, but with no pressure." (33-year-old noncarrier, high-likelihood family history)

"Anyone who wants [testing] should have the option... and anyone who doesn't want it, it's OK, don't do it. If some people know they can't [handle it], they shouldn't get tested." (31-year-old carrier, low-likelihood family history)

\section{Attitudes toward a streamlined pretest process}

Perceived advantages: "stepwise knowledge". Fourteen carriers were asked to indicate which pretest process was preferable: conventional pretest counseling or the streamlined pretest process implemented in this study. Eleven stated preference for the shorter process because it offered just the right amount of (rather than "too much") information at the right time (rather than too early).

"It isn't necessary to start with all the details, because you can't comprehend them. After there is a positive resultthen you should receive full explanations." (66-year-old female noncarrier, high-likelihood family history)

This preference for circumscribed pretest information did not reflect disinterest in knowledge of genetic status. The general importance of knowledge was voiced by $23 / 26$ carriers and by all noncarriers. Phrases such as "blindness" and "burying your head in the sand" were used to criticize people who do not seize the opportunity to know their genetic status. Respondents noted they would not have paid real attention to more detailed explanations at the time of testing.

"I don't think this is so relevant before-hand, because if you don't think you have the gene, then $80 \%$ [cancer risk] is just a statistic. It's like reading statistics about Asian men - what does that have to do with me?" (31-year-old carrier, low-likelihood family history)

Excessive pretest information was viewed as unnecessary and possibly burdensome, causing untoward anxiety: "looking for trouble" and "making people anxious about something they might not have." This would potentially prevent participation in screening, which respondents viewed as important to promote. Participants advocated stepwise provision of information, with detailed information given when it becomes personally pertinent, following a positive test result:

"I can now take more precautions and make sure that I don't get something bad...For me, the way in which it worked was terrific. Why 'put a healthy head in a sick bed' [worry about something before it is relevant] to begin with? All the information I needed, I received with the results." (37-yearold carrier, moderate-likelihood family history)

"There is a big difference between someone who comes for counseling because they think there is a genetic problem and want to make sure [they know everything], and someone going for screening. [For screening], limited information is sufficient-if you want to learn more, finding information is no problem, we're flooded by information." (59-year-old female noncarrier, low-likelihood family history)

\section{Concerns regarding the pretest process}

Six carriers (four with little family history of cancer) said that they were not fully aware of all implications while deciding whether to agree to be tested. However, this was not viewed as something 


\section{ORIGINAL RESEARCH ARTICLE}

that would have changed their decision to be tested, and only two suggested that pretest counseling should be provided.

"What I had was okay. Would I change it...maybe to read and understand more fully. Maybe then I wouldn't have taken the test? But I don't think all this [information] is so relevant beforehand." (31-year-old carrier, low-likelihood family history)

The two carriers (one with and one without a significant family history) who felt that pretest genetic counseling should be provided, said it was necessary for two reasons: to enable a fully informed decision and to ease coping with positive test results. These two respondents offered alternatives such as pretest group counseling and an explanatory video. Carriers met a genetic counselor only when they received their test results, and one respondent criticized the post-test session as lacking the familiarity that would have accompanied meeting a counselor who "already knows my story."

Among noncarriers, 4/10 said that although they were satisfied with the process they underwent, there should be more emphasis on explaining testing implications. A 30-year-old noncarrier with a high-likelihood family history summarized her conflict regarding pretest counseling:

"What I had was totally fine, but apparently there is no perfect [solution]. To sit for counseling before the test with all this data-it's too burdensome, I think. On the other hand, the written form, it's too vague."

\section{Recommendations regarding population screening}

All the respondents except for three carriers said they would recommend general BRCA screening for AJ. Two of these three carriers, although satisfied with their own decision to be tested, would not recommend general screening. One did not feel qualified to provide an opinion because he was a recent immigrant to Israel. The second explained that although she tells others of her own positive testing experience, she does not feel that she can make recommendations for others. A typical argument voiced by respondents was that $B R C A$ screening should become part of routine, age-related medical surveillance. Such institutionalization and normalization were regarded positively, as a means of reducing possible social labeling and personal stigma.

"If it becomes routine, it won't be so stressful because everyone will be having it...you won't be exceptional for having the test...it doesn't mean you are sick. I can only see the advantages. I don't see what disadvantage there could be to having a test that could save your life." (59-year-old female noncarrier, low-likelihood family history).

\section{DISCUSSION}

In this qualitative study, we sought to explore in depth the experience of participants in a screening trial. We focused on themes specific to the screening paradigm rather than to predictive $B R C A$ testing in general. Participants in this study-carriers and noncarriers, those with or without a suggestive family history-indicated high overall satisfaction with the screening process. Their main motivation was similar to that of individuals who undergo traditional clinical testing: ${ }^{17-19}$ the desire to know their genetic status in order to reduce cancer risks.

Some themes were specific to those with a suggestive family history who saw screening as a way to ease testing access and dissociate individual testing from the need for familial cooperation. Other themes were universal. All respondents noted the need for post-testing psychological services. Anxiety and stress naturally accompany recent knowledge of carrier status, similarly to carriers identified through traditional clinical testing. ${ }^{20-22}$ Although pathological distress was only rarely observed ${ }^{13,22}$ and remorse was very rare, there was a need for psychological support. Participants noted insufficient awareness and support by medical personnel at all stages of the process. Before testing, this was experienced by those with a suggestive family history as lack of referral or even discouragement of testing. After testing, carriers with sparse family history faced criticism for being "trouble seekers," aggravating uncertainty about the meaning of carrier status in this context. ${ }^{23}$ Participants indicated that routinization of genetic testing could resolve these issues. This would increase professional and public awareness and knowledge of testing and risk-reducing measures, creating a more informed and accepting environment.

Consistent with their call to routinization, the vast majority of participants-both carriers and noncarriers-recommended implementation of population screening. However, potential downsides of routinization were also recognized. Autonomy might be curtailed if genetic screening effectively becomes mandatory, as in the case of mammography, which is a healthquality measure in many countries. Health services would also need to rise to the challenge of a greater number of carriers, addressing their medical and psychological needs. These caveats are similar to those indicated by AJ BRCA carriers from families with low cancer prevalence. ${ }^{23}$

We also explored participants' views on the streamlined testing process: pretest written information and post-test genetic counseling only for carriers and for noncarriers with a significant family history. Interestingly, streamlining was perceived as offering just the right amount of information at the right time. The bioethical literature on genetic testing has emphasized a dichotomous view of autonomy: choosing either to know or not to know. The findings of this study provide a more nuanced, contingent, and contextual articulation, suggesting a construct we termed "stepwise knowledge": participants felt that the knowledge/information necessary to make an informed decision to be tested is not the same as the knowledge/information needed after being identified as a carrier. In fact, this is the pathway familiar to patients and providers in most areas of medicine: patients consent to testing based on an adequate explanation of testing indication and rationale, but detailed discussions by the physician and further pursuit of medical 
knowledge by the patient are generally limited to those with a positive test result. Consistent with this framework, quantitative analysis of the entire screening trial showed that post-test knowledge increased in those participants whose test results had medical consequences, such as carriers and noncarriers with a suggestive family history. ${ }^{13}$

Notably, concern with the lack of in-person pretest counseling was significantly less common for carriers $(2 / 26)$ than for noncarriers (4/10). It is compelling to speculate that carriers dealing with the reality of a positive test result may consider pretest counseling as less important than noncarriers, who can only hypothesize about how they would have felt if they were carriers. However, we could not find any explicit explanations for this difference in the respondents' interviews. Previous studies found that individuals who used direct-to-consumer $B R C A$ testing were unconcerned about the lack of pretest counseling, ${ }^{24}$ whereas individuals who received pretest and post-test counseling for $B R C A$ testing recommended receiving both. ${ }^{23}$ This suggests that people may tend to be satisfied with whatever process they underwent, particularly if it was of their own choice. The familiarity of medical stepwise knowledge may contribute to the increasing popularity of direct-to-consumer genetic testing-tested individuals plan to seek additional information predicated on their test results. However, after testing, whereas direct-to-consumer can leave patients stranded, a screening program within the medical system can provide the necessary care and support. Such support has been shown to improve psychosocial adaptation of individuals with cancer predisposition. ${ }^{25}$

Discussions regarding the psychosocial implications of $B R C A$ population screening have been dominated by the issues of knowledge and anxiety. ${ }^{26}$ For participants in the screening trial, both our quantitative analysis ${ }^{13}$ and this qualitative study showed that although these are areas of concern, they are viewed as secondary. The vast majority supported $B R C A$ population screening for the sake of risk assessment and cancer prevention. In this respect, participants had a clear vision of the major goals of a medical screening program. Such programs (e.g., mammography, fecal occult blood testing, cholesterol testing) are assessed based on their effects on morbidity and mortality. By contrast, where genetic testing is concerned, knowledge and anxiety prevention are often regarded as the primary outcomes. ${ }^{27}$ This may reflect the history of predictive testing: for nontreatable adult disease (e.g., Huntington disease), the main testing outcomes are indeed psychological. ${ }^{28}$ However, for medically actionable findings such as deleterious $B R C A$ mutations, ${ }^{29}$ health outcomes, including those of surveillance and prevention uptake, should be the primary measures of effectiveness. ${ }^{30}$ Notably, in this study, all post-childbearing carriers interviewed had undergone risk-reducing salpingo-oophorectomy.

Psychological distress also accompanies positive screen results for mammography, fecal occult blood testing, or cholesterol levels. ${ }^{31-33}$ However, this has not been viewed as an argument against screening, but rather as a stimulus for developing programs to improve awareness, education, compliance, and coping. ${ }^{30} \mathrm{~A} B R C A$ population screening program should certainly aim to optimize the testing process, but surmountable psychosocial concerns should not preclude screening. Future studies could directly compare various alternatives, such as those proposed by the respondents (e.g., pretest group counseling, an explanatory video, and decision aids). ${ }^{34}$

Limitations of this study are that it was performed in AJ, a community with a long history of carrier screening. "Elective" uptake of preconceptual genetic testing in $\mathrm{AJ}$ is exceptionally high and even perceived by many $\mathrm{AJ}$ as a moral duty ${ }^{35-37}$ The number of carriers identified in any screening program will be small, as is the sample size in this study. Participants were highly educated and health-aware, but are probably representative of future participants in clinical screening. ${ }^{13}$ Reflections regarding health-system implications may differ in societies where citizens are not universally insured. Nevertheless, because $B R C A$ screening is likely to first be implemented for AJ, the themes emerging from this study can inform the appropriate design of screening programs.

\section{SUPPLEMENTARY MATERIAL}

Supplementary material is linked to the online version of the paper at http://www.nature.com/gim

\section{ACKNOWLEDGMENTS}

This study was supported by a grant from the Breast Cancer Research Foundation (NY) (to E.L.L.). The authors thank Vered Colthof for administrative assistance with patient recruitment.

\section{DISCLOSURE}

The authors declare no conflict of interest.

\section{REFERENCES}

1. King MC, Levy-Lahad E, Lahad A. Population-based screening for BRCA1 and BRCA2: 2014 Lasker Award. JAMA 2014;312:1091-1092.

2. Foulkes WD, Knoppers BM, Turnbull C. Population genetic testing for cancer susceptibility: founder mutations to genomes. Nat Rev Clin Oncol 2016;13: 41-54.

3. Manchanda R, Loggenberg K, Sanderson S, et al. Population testing for cancer predisposing BRCA1/BRCA2 mutations in the Ashkenazi-Jewish community: a randomized controlled trial. J Nat/ Cancer Inst 2015;107:379.

4. Roa BB, Boyd AA, Volcik K, Richards CS. Ashkenazi Jewish population frequencies for common mutations in BRCA1 and BRCA2. Nat Genet 1996;14:185-187

5. Frank TS, Deffenbaugh AM, Reid JE, et al. Clinical characteristics of individuals with germline mutations in BRCA1 and BRCA2: analysis of 10,000 individuals. J Clin Oncol 2002;20:1480-1490.

6. Rosenthal E, Moyes K, Arnell C, Evans B, Wenstrup RJ. Incidence of BRCA1 and $B R C A 2$ non-founder mutations in patients of Ashkenazi Jewish ancestry. Breast Cancer Res Treat 2015;149:223-227.

7. King MC, Marks JH, Mandell JB; New York Breast Cancer Study Group. Breast and ovarian cancer risks due to inherited mutations in BRCA1 and BRCA2. Science 2003;302:643-646.

8. Gabai-Kapara E, Lahad A, Kaufman B, et al. Population-based screening for breast and ovarian cancer risk due to BRCA1 and BRCA2. Proc Natl Acad Sci USA 2014;111:14205-14210.

9. Domchek SM, Friebel TM, Singer CF, et al. Association of risk-reducing surgery in BRCA1 or BRCA2 mutation carriers with cancer risk and mortality. JAMA 2010;304:967-975.

10. Goel V. Appraising organised screening programmes for testing for genetic susceptibility to cancer. BMJ 2001;322:1174-1178.

11. Godard B, ten Kate L, Evers-Kiebooms G, Aymé S. Population genetic screening programmes: principles, techniques, practices, and policies. Eur J Hum Genet 2003;11:2 


\section{ORIGINAL RESEARCH ARTICLE}

12. Manchanda R, Legood R, Burnell M, et al. Cost-effectiveness of population screening for BRCA mutations in Ashkenazi jewish women compared with family history-based testing. J Nat/ Cancer Inst 2015;107:380

13. Lieberman $S$, Tomer $A$, Ben Chetrit $A$, et al. Towards population screening for $B R C A 1 / B R C A 2$ founder mutations in Ashkenazi Jews: Proactive recruitment compared with self-referral. Genet Med, in press.

14. Metcalfe KA, Poll $A$, Royer $R$, et al. Screening for founder mutations in $B R C A 1$ and BRCA2 in unselected Jewish women. J Clin Oncol 2010;28:387-391.

15. Strauss A, Corbin J (eds). Basics of Qualitative Research: Grounded Theory Procedures and Techniques. Sage: Newbury Park, CA, 1990.

16. Denzin NK, Lincoln YS (eds). Handbook of Qualitative Research. 2nd edition. Sage: Thousand Oaks, CA, 2000

17. d'Agincourt-Canning L. A gift or a yoke? Women's and men's responses to genetic risk information from BRCA1 and BRCA2 testing. Clin Genet 2006;70:462-472.

18. Brunstrom K, Murray A, McAllister M. Experiences of women who underwent predictive BRCA1/2 mutation testing before the age of 30. J Genet Couns 2016:25:90-100

19. Hamilton R, Williams JK, Skirton H, Bowers BJ. Living with genetic test results for hereditary breast and ovarian cancer. J Nurs Scholarsh 2009;41: 276-283

20. Watson M, Foster C, Eeles R, et al.; Psychosocial Study Collaborators Psychosocial impact of breast/ovarian (BRCA1/2) cancer-predictive genetic testing in a UK multi-centre clinical cohort. Br J Cancer 2004;91: 1787-1794.

21. Graves KD, Vegella P, Poggi EA, et al. Long-term psychosocial outcomes of $B R C A 1 / B R C A 2$ testing: differences across affected status and risk-reducing surgery choice. Cancer Epidemiol Biomarkers Prev 2012;21:445-455.

22. Ringwald J, Wochnowski C, Bosse $K$, et al. Psychological distress, anxiety, and depression of cancer-affected BRCA1/2 mutation carriers: a systematic review. J Genet Couns 2016:25:880-891.

23. Shkedi-Rafid S, Ofer-Bialer G, Meiner V, Calderon-Margalit R. Clinicians attitudes toward general screening of the Ashkenazi-Jewish population for prevalent founder BRCA1/2 and LRRK2 mutations. Public Health Genomics 2013:16:174-183.

24. Francke U, Dijamco C, Kiefer AK, et al. Dealing with the unexpected: consumer responses to direct-access BRCA mutation testing. PeerJ 2013;1:e8.
25. Heiniger L, Price MA, Charles M, Butow PN; kConFab Psychosocial Group on behalf of the $\mathrm{kConFab}$ Investigators. Facilitators and challenges in psychosocial adaptation to being at increased familial risk of breast cancer. J Genet Couns 2015:24:890-907.

26. Yurgelun MB, Hiller E, Garber JE. Population-wide screening for Germline BRCA1 and BRCA2 mutations: too much of a good thing? J Clin Oncol 2015;33:3092-3095.

27. Armstrong J, Toscano $\mathrm{M}$, Kotchko $\mathrm{N}$, et al. Utilization and outcomes of $B R C A$ genetic testing and counseling in a national commercially insured population: the ABOUT study. JAMA Onco/ 2015;1:1251-1260.

28. Broadstock M, Michie S, Marteau T. Psychological consequences of predictive genetic testing: a systematic review. Eur J Hum Genet 2000;8:731-738.

29. Green RC, Berg JS, Grody WW, et al.; American College of Medical Genetics and Genomics. ACMG recommendations for reporting of incidental findings in clinical exome and genome sequencing. Genet Med 2013;15:565-574.

30. Narod S. Genetic Testing for BRCA Mutations Today and Tomorrow-About the ABOUT Study. JAMA Oncol 2015;1:1225-1226.

31. Laing SS, Bogart A, Chubak J, Fuller S, Green BB. Psychological distress after a positive fecal occult blood test result among members of an integrated healthcare delivery system. Cancer Epidemiol Biomarkers Prev 2014:23:154-159.

32. Gillespie C. The experience of risk as 'measured vulnerability': health screening and lay uses of numerical risk. Sociol Health IIIn 2012:34:194-207.

33. Nelson HD, Pappas M, Cantor A, Griffin J, Daeges M, Humphrey L. Harms of breast cancer screening: systematic review to update the 2009 U.S. Preventive Services Task Force Recommendation. Ann Intern Med 2016;16:256-67.

34. Wakefield CE, Meiser B, Homewood J, Ward R, O'Donnell S, Kirk J; Australian GENetic testing Decision Aid Collaborative Group. Randomized trial of a decision aid for individuals considering genetic testing for hereditary nonpolyposis colorectal cancer risk. Cancer 2008;113:956-965.

35. Raz AE, Schicktanz S. Diversity and uniformity in genetic responsibility: moral attitudes of patients, relatives and lay people in Germany and Israel. Med Health Care Philos 2009:12:433-442.

36. Hashiloni-Dolev Y (ed). A Life (Un)Worthy of Living. Springer: Dodrecht, The Netherlands, 2007

37. Sher C, Romano-Zelekha O, Green MS, Shohat T. Factors affecting performance of prenatal genetic testing by Israeli Jewish women. Am J Med Genet A 2003;120A:418-422. 